\title{
Variations in serum transforming growth factor- $\beta 1$ levels with gender, age and lifestyle factors of healthy Japanese adults
}

\author{
Yingsong Lin ${ }^{\mathrm{a}, *}$, Kei Nakachi ${ }^{\mathrm{b}}$, Yoshinori Ito ${ }^{\mathrm{c}}$, Shogo Kikuchi ${ }^{\mathrm{a}}$, Akiko Tamakoshi ${ }^{\mathrm{a}}$, Kiyoko Yagyu $^{\mathrm{a}}$, \\ Yoshiyuki Watanabe ${ }^{\mathrm{d}}$, Yutaka Inaba ${ }^{\mathrm{e}}$ and Kazuo Tajima ${ }^{\mathrm{f}}$ for the JACC Study Group \\ ${ }^{a}$ Department of Public Health, Aichi Medical University School of Medicine, Nagakute, Japan \\ ${ }^{\mathrm{b}}$ Department of Radiobiology/Molecular Epidemiology, Radiation Effects Research Foundation, Hiroshima, Japan \\ ${ }^{\mathrm{c}}$ Department of Preventive Medicine/Biostatistics and Medical Decision Making, Nagoya University Graduate \\ School of Medicine, Nagoya, Japan \\ ${ }^{\mathrm{d}}$ Department of Epidemiology for Community Health and Medicine, Kyoto Prefectural University of Medicine \\ Graduate School of Medical Science, Kyoto, Japan \\ e Division of Public Health, Department of Food and Health Sciences, Faculty of Human Life Sciences, Jissen \\ Women's University, Tokyo, Japan \\ ${ }^{\mathrm{f}}$ Aichi Cancer Center Research Institute, Nagoya, Japan
}

\begin{abstract}
Elevated serum or plasma Transforming Growth Factor- $\beta 1$ (TGF- $\beta 1$ ) levels have been linked to cancer and other diseases in numerous studies; however, very few studies have reported an association between circulating TGF- $\beta 1$ and lifestyle factors in healthy people. We examined the association between serum TGF- $\beta 1$ levels and gender, age, body mass index (BMI), smoking, and drinking in a large population-based cohort study $(\mathrm{N}=9,142)$. Serum TGF- $\beta 1$ levels were detected by the Quantikine enzyme-linked immunoassay kit $(\mathrm{R} \& \mathrm{D}$ Systems). The data indicated highly significant $(\mathrm{p}<0.0001)$ difference in serum TGF- $\beta 1$ levels between men (mean value: $37.6 \pm 0.12 \mathrm{ng} / \mathrm{mL}, \mathrm{N}=4888$ ) and women (mean value: $35.1 \pm 0.12 \mathrm{ng} / \mathrm{ml}$, $\mathrm{N}=4254$ ). Serum TGF- $\beta 1$ levels decreased with age (trend $p<0.0001$ ) and were positively associated with obesity (trend $p<0.0001$ ) in both men and women. We observed a significant trend with increased serum TGF- $\beta 1$ levels corresponding to increased amount of tobacco and alcohol consumption in men (trend $p<0.0001$ ). These findings suggest that serum TGF- $\beta 1$ levels appear to be modulated by gender, age and lifestyle factors such as obesity, cigarette smoking, and alcohol drinking in healthy Japanese adults.
\end{abstract}

Keywords: Serum TGF- $\beta 1$, gender, age, smoking, obesity

\section{Introduction}

Transforming growth factor- $\beta$ (TGF- $\beta$ ) is polypeptides that regulate several cellular functions, including cell growth, differentiation, motility, and extra cellular

* Corresponding author: Yingsong Lin, Department of Public Health, Aichi Medical University School of Medicine, Japan. Tel.: +81561623311 Fax: +8156162 5270; E-mail: linys@aichi-medu.ac.jp. matrix production [1]. Recent studies have also underscored the essential role of TGF- $\beta$ in maintenance of immune homeostasis [2]. TGF- $\beta$ regulates immune cells that are involved in both innate and adaptive immune response, exerting its immunosuppressive effects through inhibiting the function of inflammatory cells and promoting the function of regulatory $\mathrm{T}$ cells [3].

TGF- $\beta$ has three isoforms, of which TGF- $\beta 1$ is the most abundant and universally expressed isoform. Circulating levels of TGF- $\beta 1$ can be measured and have 
shown a potential usefulness as a prognostic marker for human diseases. High serum levels of TGF- $\beta 1$ have been found in patients with invasive prostate, breast, or colorectal cancer as compared with healthy control subjects [1,4-6]. Furthermore, the overexpression of TGF- $\beta 1$ in cancer tissues and higher circulating levels significantly correlate with tumor progression, metastasis, angiogenesis and poor prognostic outcome [7-9].

Previous studies have shown a considerable variation in plasma TGF- $\beta 1$ levels among healthy individuals, with the reported values greater than 100-fold range [10]. Besides, very few studies have examined the relationship between circulating TGF- $\beta 1$ levels and lifestyle factors in healthy individuals. The aim of this study is to assess variations in serum TGF- $\beta 1$ levels with gender, age and lifestyle factors among middleaged and elderly Japanese individuals, the finding of which may be applied to potentially evaluate cancer risk in Japanese population.

\section{Methods}

The study population included healthy control subjects in a nested case-control study within a large cohort study, Japanese Collaborative Cohort Study for Evaluation of Cancer Risk (the JACC study). Details of the JACC Study have been described previously [12]. Briefly, the aim was to evaluate the association between lifestyle factors and cancer risk in middle-aged and elderly Japanese. Between 1988 and 1990, 110,792 subjects aged 40-79 years were recruited from 45 areas throughout Japan and subsequently followed up for mortality. Baseline data were collected through a self-administered questionnaire including information on demographic characteristics, medical history, and lifestyle factors such as cigarette smoking, alcohol drinking, and dietary habits. In addition, 35\% of the cohort participants donated blood samples upon our request, and the sera were kept at $-80^{\circ} \mathrm{C}$ until analyses.

In the present study, we evaluated the association of serum TGF- $\beta 1$ levels with age and selected lifestyle factors such as smoking, drinking and obesity in 9142 control subjects (4888 men and 4254 women) who came from a nested case-control study within the JACC Study. Those with missing data on TGF- $\beta 1$ levels and each lifestyle factor were excluded.

Detailed information on lifestyle factors was collected using a self-administered questionnaire. For cigarette smoking, subjects were asked to describe their smoking status (current, former, or never) and to respond to smoking-related questions including age at which smoking started, the number of cigarettes smoked per day, and years of smoking. In the section of alcohol drinking, we first asked the subjects to report their drinking status (nondrinker, ex-drinker, or current drinker). Data on the frequency of consumption, the type of beverages and the average amount of consumption on one occasion were further collected for ex-drinkers or current drinkers. Body weight and height were self-reported, and body mass index (BMI) was calculated as weight in kilograms divided by height in meters squared.

Informed consent was obtained mainly by having the subjects sign on the cover of the questionnaire; however, the community leaders in some study areas gave the consent for participating in the study on representative of the local residents. The JACC Study was approved by the Ethics Committee of Nagoya University School of Medicine.

\subsection{Biochemical assay of sera}

Serum TGF- $\beta 1$ levels were measured by a quantitative sandwich enzyme immunoassay technique using a Quantikine human TGF- $\beta 1$ kit, according to the manufacturer's instructions (R\&D Systems, Minneapolis, $\mathrm{MN})$. For serum preparation [11], the time of clotting is 30 minutes at room temperature. Then samples were centrifuged for 10 minutes at approximately $1000 \mathrm{x}$ $\mathrm{g}$ after incubation. All samples were assayed at a single laboratory (SRL Inc., Hachioji). The intra-assay coefficient of variation for quality control samples ranged from 2.67 to $6.79 \%$ (13).

\subsection{Statistical analysis}

Since serum TGF- $\beta 1$ levels seemed normally distributed for both men and women, we used raw measurement data in all analyses. Age- and area-adjusted least square means of serum TGF- $\beta 1$ levels across categories of BMI, smoking and drinking were estimated using analysis of covariance methods. Analysis of covariance methods were also used to test for trends in TGF- $\beta 1$ levels across each category. Statistical analyses were conducted using SAS Release 9.1 (SAS Institute, Cary, NC). 
Table 1

Mean values of serum TGF- $\beta 1^{*}$ levels in subcohorts of healthy Japanese adults classified by selected lifestyle factors

\begin{tabular}{|c|c|c|c|c|c|c|c|c|c|}
\hline & \multirow[b]{2}{*}{ Category } & \multicolumn{4}{|c|}{$\operatorname{Men}(\mathrm{N}=4888)$} & \multicolumn{4}{|c|}{ Women $(\mathrm{N}=4254)$} \\
\hline & & $\mathrm{N}$ & TGF- $\beta 1$ & $\mathrm{SE}^{* * *}$ & Trend & $\mathrm{N}$ & TGF- $\beta 1$ & $\mathrm{SE}^{* * *}$ & Trend \\
\hline Gender & Entire cohort $(\mathrm{N}=9142)$ & 4888 & 37.6 & 0.12 & & 4254 & 35.1 & 0.12 & $P<0.0001$ \\
\hline \multirow[t]{4}{*}{ Age (Yr) } & $40-49$ & 282 & 40.6 & 0.52 & Negative & 397 & 36.9 & 0.46 & Negative \\
\hline & $50-59$ & 1104 & 38.7 & 0.27 & correlation & 960 & 35.7 & 0.35 & correlation \\
\hline & $60-69$ & 2585 & 36.9 & 0.21 & $(p<0.0001)$ & 1849 & 35.0 & 0.29 & $(p<0.0001)$ \\
\hline & $70-79$ & 917 & 34.2 & 0.30 & & 1048 & 33.4 & 0.34 & \\
\hline \multirow{3}{*}{$\mathrm{BMI}^{* *}\left(\mathrm{~kg} / \mathrm{m}^{2}\right)$} & $<18.5$ & 272 & 36.3 & 0.53 & Positive & 286 & 32.8 & 0.51 & Positive \\
\hline & $18.5-24.9$ & 3779 & 37.5 & 0.21 & correlation & 2947 & 35.3 & 0.28 & correlation \\
\hline & $\geqq 25.0$ & 837 & 38.4 & 0.32 & $(p<0.0001)$ & 1021 & 36.2 & 0.34 & $(p<0.0001)$ \\
\hline \multirow[t]{3}{*}{ Cigarette smoking } & Former and never & 2468 & 37.4 & 0.23 & Positive & 4133 & 35.4 & 0.28 & No \\
\hline & Current, 1-19 cigarettes/day & 902 & 37.3 & 0.33 & correlation & 85 & 35.2 & 0.84 & correlation \\
\hline & Current, $\geqq 20$ cigarettes/day & 1501 & 38.1 & 0.27 & $(p<0.0001)$ & 29 & 36.1 & 1.41 & $(p=0.77)$ \\
\hline \multirow[t]{3}{*}{ Alcohol drinking } & Former and never & 1276 & 37.0 & 0.30 & Positive & 3421 & 35.5 & 0.29 & No \\
\hline & Current, $<23$ g/day & 673 & 37.5 & 0.37 & correlation & 413 & 35.1 & 0.45 & correlation \\
\hline & Current, $\geqq 23 \mathrm{~g} /$ day & 2050 & 38.2 & 0.27 & $(p<0.0001)$ & 68 & 35.6 & 0.95 & $(p=0.28)$ \\
\hline
\end{tabular}

${ }^{*}$ TGF- $\beta 1$ (ng/mL), Transforming growth factor- $\beta 1$.

${ }^{* *}$ BMI, body mass index.

*** SE, standard error of the means.

\section{Results}

The summary of data for the entire population-based cohort study $(\mathrm{N}=9142)$ is presented in Table 1 . Mean values of serum TGF- $\beta 1$ levels in subcohorts of healthy Japanese adults were classified by gender, age, and lifestyle factors such as obesity, cigarette smoking and alcohol drinking (Table 1). The results indicate highly significant $(p<0.0001)$ difference in serum TGF- $\beta 1$ levels between men (mean value: $37.6 \pm 0.12 \mathrm{ng} / \mathrm{ml}, \mathrm{N}$ $=4880$ ) and women (mean value: $35.1 \pm 0.12 \mathrm{ng} / \mathrm{mL}$, $\mathrm{N}=4254$ ). When men and women were divided into 10 -year age groups, men had higher serum TGF- $\beta 1$ levels in each group compared with women. Serum TGF- $\beta 1$ levels were inversely associated with age in both men and women, with decreasing serum levels as age advanced (Table 1$)$.

Serum TGF- $\beta 1$ levels were positively associated with obesity (Table 1). Both men and women whose BMI were 25.0 or more had higher serum TGF- $\beta 1$ levels compared with those whose BMI were less than 18.5 (trend $P<0.0001$ ).

Men who smoked 20 or more cigarettes per day had higher mean serum TGF- $\beta 1$ levels compared with nonsmokers and current smoker who smoked less than 20 cigarettes per day (Table 1 ). Serum TGF- $\beta 1$ levels increased with increasing amount of smoking (trend $P<$ 0.0001). Serum TGF- $\beta 1$ levels were also positively associated with alcohol drinking in men (Table 1), with those who drank $23 \mathrm{~g}$ or more of alcohol experiencing higher serum TGF- $\beta 1$ (trend $P=0.0008$ ). In women, however, no significant trend was observed in elevated TGF- $\beta 1$ associated with either smoking (trend $P=$ 0.77 ) or drinking (trend $P=0.28$ ).

\section{Discussion}

We examined the association between serum TGF$\beta 1$ levels and gender, age, and selected lifestyle factors in a large number of healthy control subjects, and found that serum TGF- $\beta 1$ levels appear to be modulated in part by gender, age and lifestyle factors such as obesity, cigarette smoking, and alcohol drinking.

In this study, men had higher serum TGF- $\beta 1$ levels in each group compared with women, and serum TGF$\beta 1$ levels decreased with increasing age in both men and women. The inverse association observed with age was consistent with another study of healthy Japanese individuals, which showed an age-dependent decrease with serum TGF- $\beta 1$ levels being significantly higher in children when compared with adults [14]. However, in previous study by Grainger et al. [10], no significant association was observed between plasma TGF- $\beta 1$ levels and age in a meta-analysis of 1,006 healthy Europeans subjects. Since this study used the same Quantikine ELISA kit, other factors such as genetic background of the study subjects, different blood compartments, and methods of sample preparation may have contributed to the inconsistent results. The association between serum TGF- $\beta 1$ levels and aging seems complex because of the dual role of TGF- $\beta 1$ in human disease. While increased activity occurs in patients with progressive cancers, decreased activity could be observed in early tumorigenesis or atherosclerosis [1]. The age-related decline in serum TGF- $\beta 1$ levels observed in our study suggests that decreased production of TGF- $\beta 1$ might be involved in aging process. Since aging is characterized by a decrease in bone volume, there has been 
evidence showing that the skeletal content of TGF- $\beta 1$ and IGF-1 decreased linearly with age (15). This indicates that the growth factor content of the bone could decrease as a function of aging.

We found that serum TGF- $\beta 1$ levels increased with increasing BMI in both men and women. Several lines of evidence were available to support a positive association between TGF- $\beta 1$ and obesity. Porreca et al. reported that TGF- $\beta 1$ levels were significantly elevated in hypertensive obese patients compared with hypertensive patients with normal BMI [16]. In adipose tissue from both obese mice and humans, the levels of tissue TGF- $\beta 1$ antigen have been shown to correlate well with BMI [17]. Moreover, TGF- $\beta 1$ gene was associated with obesity phenotypes such as BMI, fat mass, and lean mass in a large sample of white population [18]. Likewise, an association between TGF- $\beta 1$ polymorphism and both BMI and abdominal obesity was observed in Swedish men [19].

Until now information regarding the effect of smoking or drinking on serum TGF- $\beta 1$ levels was not available. We found that high amount of tobacco consumption was associated with elevated serum TGF- $\beta 1$ levels among men. One possible explanation for this positive association relates to the immunosuppressive effect of TGF- $\beta 1$ on immune system. Chronic inhalation of cigarette smoke alters a wide range of immunological functions, including both innate and adaptive immune responses [20]. Smokers develop airway inflammation through oxidative stress with the involvement of immune cells including macrophages, lymphocytes, and natural killer (NK)-cells [20]. It has been shown that smokers had significantly lower NK cell activity compared with nonsmokers [21], and high natural cytotoxic activity of peripheral-blood lymphocytes has been associated with a decreased cancer risk in a prospective cohort study [22]. In response to cigarette smoke lung epithelium may increase the release of TGF- $\beta 1$ to regulate those inflammatory cells. The mRNA levels have been shown to be significantly higher in small airway epithelium in smokers when compared with nonsmokers [23].

The strengths of our study include a large sample size, sex-specific analysis, a detailed collection of lifestyle factors such as smoking and drinking, and the ability to adjust for other confounding factors. Our study also has limitations. A causal effect between lifestyle factors and serum TGF- $\beta 1$ cannot be proved with our cross-sectional analysis. A longitudinal analysis would be more suitable to examine long term influences, but few such studies have been reported. Anoth- er limitation is that we only measured serum TGF- $\beta 1$ at baseline. Using one point measurement might have failed to catch the variations in TGF- $\beta 1$ levels, given the dual role that TGF- $\beta 1$ plays in disease process.

In conclusion, serum TGF- $\beta 1$ levels appear to be modulated by gender, age and lifestyle factors such as obesity, cigarette smoking, and alcohol drinking in healthy Japanese adults.

\section{Acknowledgments}

The JACC Study has been supported by Grants-inAid for Scientific Research from the Ministry of Education, Science, Sports and Culture of Japan (Monbusho), and Grants-in-Aid for Scientific Research on Priority Areas of Cancer, as well as Grant-in-Aid for Scientific Research on Priority Areas of Cancer Epidemiology from the Japanese Ministry of Education, Culture, Sports, Science and Technology (Monbu-Kagakusho) (Nos. 61010076, 62010074, 63010074, 1010068, 2151065, 3151064, 4151063, 5151069, 6279102, 11181101, 17015022 and 18014011).

The authors thank Dr. Kunio Aoki, Professor Emeritus, Nagoya University School of Medicine and the former chairperson of the JACC Study, and Dr. Haruo Sugano, the former Director of the Cancer Institute, Tokyo, for their contribution in the initiation of the JACC Study.

\section{Member list of the JACC Study Group}

The present members of the JACC Study who coauthored this paper together with their affiliations are as follows: Dr. Akiko Tamakoshi (present chairman of the study group), Aichi Medical University School of Medicine; Drs. Mitsuru Mori \& Fumio Sakauchi, Sapporo Medical University School of Medicine; Dr. Yutaka Motohashi, Akita University School of Medicine; Dr. Ichiro Tsuji, Tohoku University Graduate School of Medicine; Dr. Yosikazu Nakamura, Jichi Medical School; Dr. Hiroyasu Iso, Osaka University School of Medicine; Dr. Haruo Mikami, Chiba Cancer Center; Dr. Michiko Kurosawa, Juntendo University School of Medicine; Dr. Yoshiharu Hoshiyama, University of Human Arts and Sciences; Dr. Hiroshi Suzuki, Niigata University School of Medicine; Dr. Koji Tamakoshi, Nagoya University School of Medicine; Dr. Kenji Wakai, Nagoya University Graduate School of Medicine; Dr. Shinkan Tokudome, Nagoya City Uni- 
versity Graduate School of Medical Sciences; Dr. Koji Suzuki, Fujita Health University School of Health Sciences; Dr. Shuji Hashimoto, Fujita Health University School of Medicine; Dr. Shogo Kikuchi, Aichi Medical University School of Medicine; Dr. Yasuhiko Wada, Kansai Rosai Hospital; Dr. Takashi Kawamura, Kyoto University Center for Student Health; Drs. Yoshiyuki Watanabe \& Kotaro Ozasa, Kyoto Prefectural University of Medicine Graduate School of Medical Science; Dr. Tsuneharu Miki, Graduate School of Medical Science, Kyoto Prefectural University of Medicine Graduate School of Medical Science; Dr. Chigusa Date, Faculty of Human Environmental Sciences, Nara Women's University; Dr. Kiyomi Sakata, Iwate Medical University; Dr. Yoichi Kurozawa, Tottori University Faculty of Medicine; Dr. Takesumi Yoshimura, Fukuoka Institute of Health and Environmental Sciences; Dr. Yoshihisa Fujino, University of Occupational and Environmental Health; Dr. Akira Shibata, Kurume University School of Medicine; Dr. Naoyuki Okamoto, Kanagawa Cancer Center; Dr. Hideo Shio, Moriyama Municipal Hospital.

The past investigators of the study group were listed in reference 12 except for the following eight members (affiliations are those at the time they participated in the study): Dr. Takashi Shimamoto, Institute of Community Medicine, University of Tsukuba; Dr. Heizo Tanaka, Medical Research Institute, Tokyo Medical and Dental University; Dr. Shigeru Hisamichi, Tohoku University Graduate School of Medicine; Dr. Masahiro Nakao, Kyoto Prefectural University of Medicine; Dr. Takaichiro Suzuki, Research Institute, Osaka Medical Center for Cancer and Cardiovascular Diseases; Dr. Tsutomu Hashimoto, Wakayama Medical University; Dr. Teruo Ishibashi, Asama General Hospital; and Dr. Katsuhiro Fukuda, Kurume University School of Medicine.

\section{References}

[1] R. Derynck, R.J. Akhurst and A. Balmain, TGF-beta signaling in tumor suppression and cancer progression, Nat Genet 29 (2001), 117-129.

[2] M.O. Li, Y.Y. Wan, S. Sanjabi, A.K. Robertson and R.A. Flavell, Transforming growth factor-beta regulation of immune responses, Annu Rev Immunol 24 (2006), 99-146.

[3] M.O. Li and R.A. Flavell, TGF- $\beta$ : a master of all T cell trades, Cell 134 (2008), 392-404.

[4] G.C. Blobe, W.P. Schiemann and H.F. Lodish, Role of transforming growth factor beta in human disease, $N$ Engl J Med 342 (2000), 1350-1358.

[5] V. Ivanovic, A. Melman, B. Davis-Joseph, M. Valcic and J. Geliebter, Elevated plasma levels of TGF-beta 1 in patients with invasive prostate cancer, Nat Med 1 (1995), 282-284.
[6] S.M. Sheen-Chen, H.S. Chen, C.W. Sheen, H.L. Eng and W.J. Chen, Serum levels of transforming growth factor beta1 in patients with breast cancer, Arch Surg 136 (2001), 937-940.

[7] K.S. Shim, K.H. Kim, W.S. Han and E.B. Park, Elevated serum levels of transforming growth factor-betal in patients with colorectal carcinoma: its association with tumor progression and its significant decrease after curative surgical resection, Cancer 85 (1999), 554-561.

[8] V. Ivanović, M. Demajo, K. Krtolica, M. Krajnović, M. Konstantinović, V. Baltić, G. Prtenjak, B. Stojiljković, M. Breberina, Z. Nesković-Konstantinović, D. Nikolić-Vukosavljević and B. Dimitrijević, Elevated plasma TGF-beta1 levels correlate with decreased survival of metastatic breast cancer patients, Clin Chim Acta 371 (2006), 191-193.

[9] H. Saito, S. Tsujitani, S. Oka, A. Kondo, M. Ikeguchi, M. Maeta and N. Kaibara, An elevated serum level of transforming growth factor-beta 1 (TGF-beta 1) significantly correlated with lymph node metastasis and poor prognosis in patients with gastric carcinoma, Anticancer Res 20 (2000), 4489-4493.

[10] D.J. Grainger, D.E. Mosedale and J.C. Metcalfe, TGF- $\beta$ in blood: a complex problem, Cytokine Growth Factor Rev 11 (2000) 133-145.

[11] R. Dittadi, S. Meo, F. Fabris, G. Gasparini, D. Contri, M. Medici and M. Gion, Validation of blood collection procedures for the determination of circulating vascular endothelial growth factor (VEGF) in different blood compartments, Int $J$ Biol Markers 16 (2001), 87-96.

[12] A. Tamakoshi, T. Yoshimura, Y. Inaba, Y. Ito, Y. Watanabe, K. Fukuda, H. Iso and JACC Study Group, Profile of the JACC study, J Epidemiol 15 Suppl 1 (2005), S4-8.

[13] Y. Ito, K. Nakachi, K. Imai, S. Hashimoto, Y. Watanabe, Y. Inaba, A. Tamakoshi, T. Yoshimura and JACC Study Group, Stability of frozen serum levels of insulin-like growth factor-I, insulin-like growth factor-II, insulin-like growth factor binding protein-3, transforming growth factor beta, soluble Fas, and superoxide dismutase activity for the JACC study. 1: J Epidemiol 15 Suppl 1 (2005), S67-73.

[14] Y. Okamoto, Y. Gotoh, O. Uemura, S. Tanaka, T. Ando and M. Nishida, Age-dependent decrease in serum transforming growth factor (TGF)-beta 1 in healthy Japanese individuals; population study of serum TGF-beta 1 level in Japanese, Dis Markers 21 (2005), 71-74.

[15] V. Nicolas, A. Prewett, P. Bettica, S. Mohan, R.D. Finkelman, D.J.Baylink and J.R. Farley, Age-related decreases in insulinlike growth factor-I and transforming growth factor-beta in femoral cortical bone from both men and women: implications for bone loss with aging, J Clin Endocrinol Metab 78 (1994), 1011-1016.

[16] E. Porreca, C. Di Febbo, E. Vitacolonna, G. Baccante, A. Di Castelnuovo, A. Angelini, F. Febo, M. Di Nisio and F. Cuccurullo, Transforming growth factor-beta1 levels in hypertensive patients: association with body mass index and leptin, Am J Hypertens 9 (2002), 759-765.

[17] M.C. Alessi, D. Bastelica, P. Morange, B. Berthet, I. Leduc, M. Verdier, O. Geel and I. Juhan-Vague, Plasminogen activator inhibitor 1, transforming growth factor-beta1, and BMI are closely associated in human adipose tissue during morbid obesity, Diabetes 49 (2000), 1374-1380.

[18] J.R. Long, P.Y. Liu, Y.J. Liu, Y. Lu, D.H. Xiong, L. Elze, R.R. Recker and H.W. Deng, APOE and TGF-beta1 genes are associated with obesity phenotypes, J Med Genet 40 (2003), 918-924.

[19] R. Rosmond, M. Chagnon, C. Bouchard and P. Björntorp, Increased abdominal obesity, insulin and glucose levels in nondi- 
abetic subjects with a T29C polymorphism of the transforming growth factor-beta1 gene, Horm Res 59 (2003), 191-194.

[20] M. Sopori, Effects of cigarette smoke on the immune system, Nat Rev Immunol 2 (2002), 372-327.

[21] K. Nakachi and K. Imai, Environmental and physiological influences on human natural killer cell activity in relation to good health practices, Jpn J Cancer Res 83 (1992), 798-805.

[22] K. Imai, S. Matsuyama, S. Miyake, K. Suga and K. Nakachi, Natural cytotoxic activity of peripheral-blood lymphocytes and cancer incidence: an 11-year follow-up study of a general population, Lancet 356 (2000), 1795-1799.

[23] H. Takizawa, M. Tanaka, K. Takami, T. Ohtoshi, K. Ito, M. Satoh, Y. Okada, F. Yamasawa, K. Nakahara and A. Umeda, Increased expression of transforming growth factor-beta1 in small airway epithelium from tobacco smokers and patients with chronic obstructive pulmonary disease (COPD). Am J Respir Crit Care Med 163 (2001), 1476-1483. 


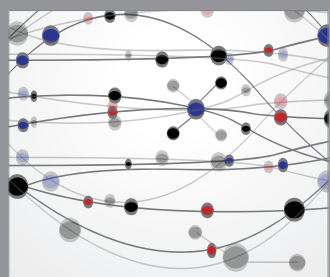

The Scientific World Journal
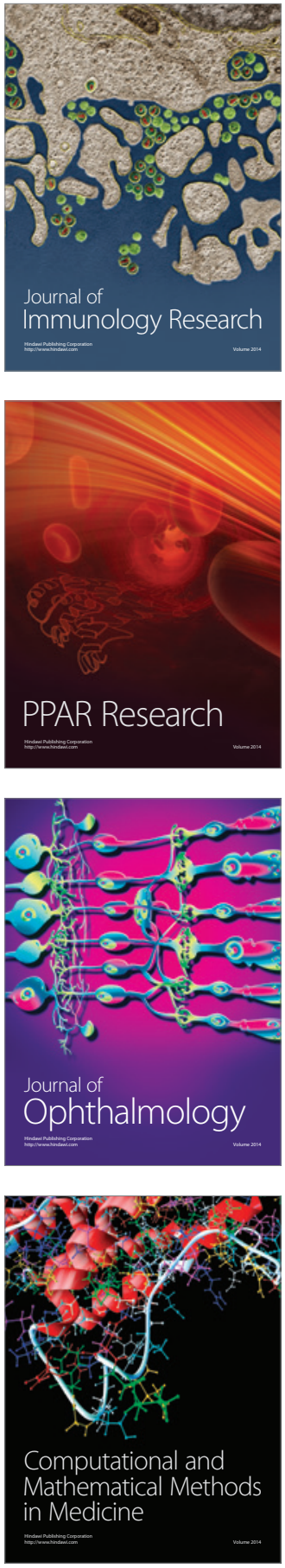

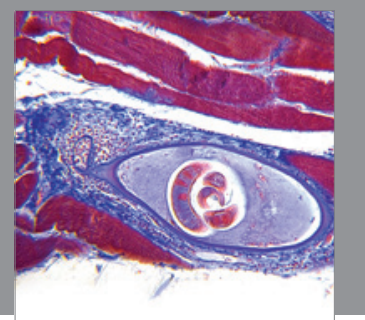

Gastroenterology

Research and Practice
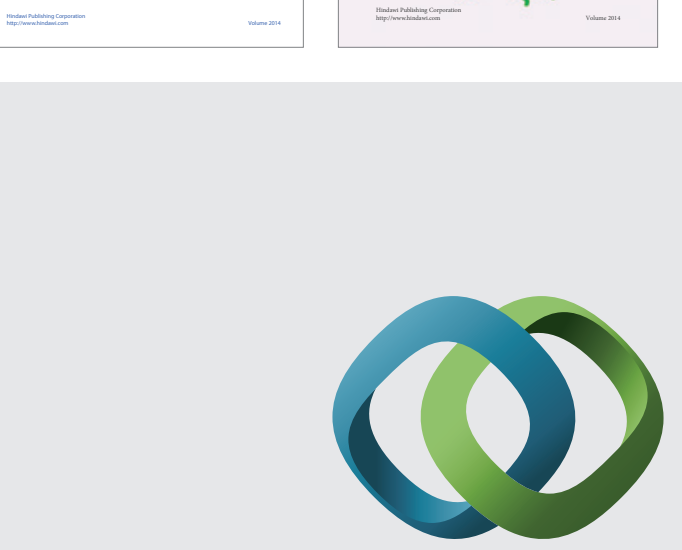

\section{Hindawi}

Submit your manuscripts at

http://www.hindawi.com
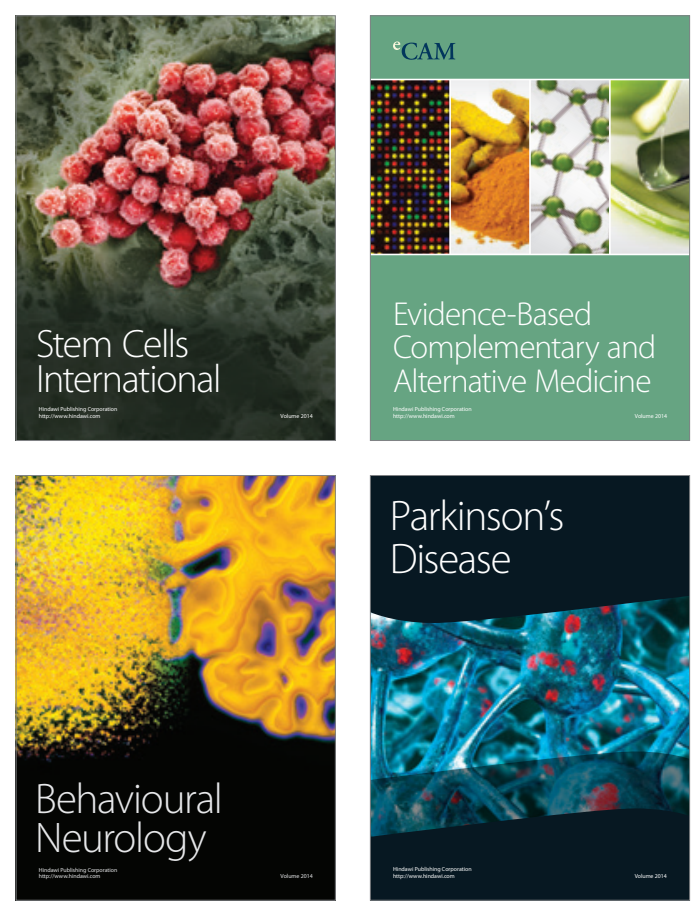

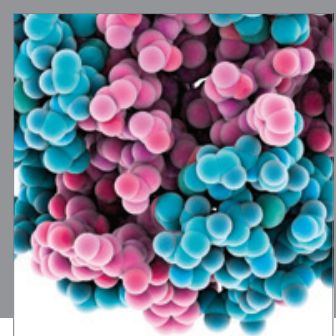

Journal of
Diabetes Research

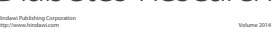

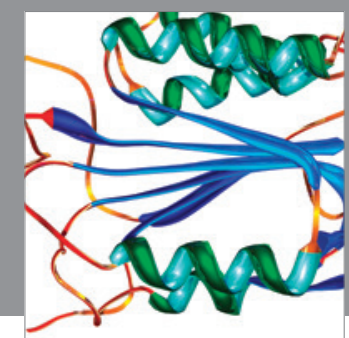

Disease Markers
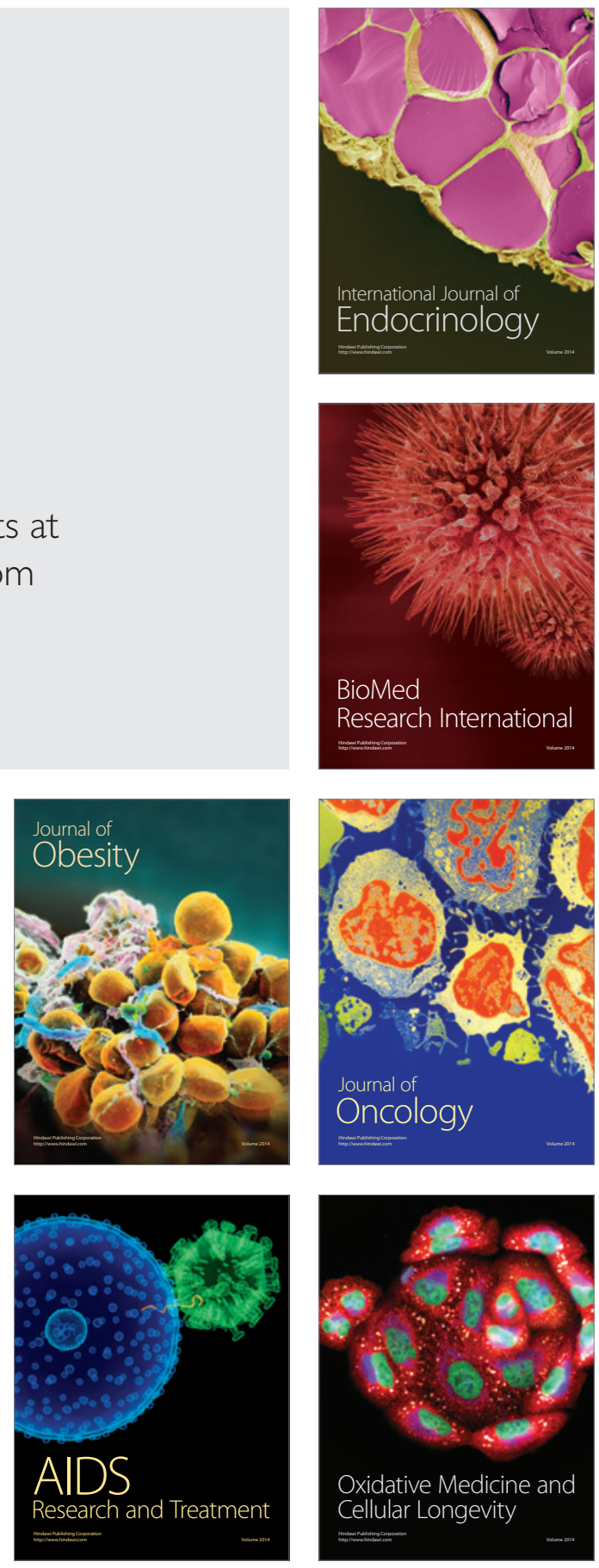